\title{
Sağlık Çalışanlarının Güvenlik İklimi Algıları ve Güvenlik Tedbirlerine Uyma Davranışlarının İncelenmesi
}

\author{
Research of Healthcare Worker's Safety Climate \\ Perceptions and Safe Work Practices
}

Ahmet Ferda ÇAKMAK, Mehpare TATLI

\begin{abstract}
ÖZET
Bu çalışma kapsamında bir üniversite hastanesinde çalışmakta olan hemşire ve doktorlardan oluşan sağlık çalışanlarının iş güvenliği tedbirlerine uyumlu davranışları ve güvenlik iklimi algıları arasındaki ilişkilerin farklı değişkenler bakımından incelenmesi amaçlanmıştır. Uygulama kapsamında 250 anket formu dağıtılmış, 192 geri dönüşle oluşan örneklem grubundan edinilen verilerle hipotezler test edilmiştir. Yapılan analizler sonucunda, katılımcıların meslekteki toplam tecrübeleri ile çalıştıkları ortamda iş güvenliği tedbirlerine uyumlu davranış gösterme ve güvenlik iklimini olumlu algllama seviyesi birbirleri ile pozitif yönlü olarak ilişkili bulunmuştur. Kurumda daha önce yönetim görevi yerine getiren çalışanlar için tüm güvenlik iklimi faktörleri anlamlı düzeyde farklılık göstererek daha olumlu seviyede tespit edilmiştir. Bununla birlikte uyumlu davranış gösterme eğilimi iki grup açısından anlamlı düzeyde farklılık göstermemektedir.
\end{abstract}

Anahtar Kelimeler: Güvenlik Kültürü, Güvenlik İklimi Algısı, Güvenlik Tedbirlerine Uyma Davranışı, İş Kazası Riskleri

\begin{abstract}
In this study, that was aimed to investigate according to different variables the relationships between the safe work practices and the safety climate perceptions of nurses and doctors in a university hospital. Within the scope of the application, 250 questionnaires were distributed and the hypotheses were tested with data obtained from the group of 192 samples returned. As a result of the analyzes, the level of positive safety climate perception and safe work practices of participants with the total experience in the profession of health employees were positively correlated with each other. For employees who have previously performed management duties at the institution, all safety climate factors have been identified at a more positive level, with significant differences. However, the tendency to safe work practices of participants did not differ significantly in terms of the two groups.
\end{abstract}

Keywords: Safety Culture, Perception of Safety Climate, Safe Work Practices, Work Accident Risks

Prof. Dr. Ahmet Ferda ÇAKMAK - Bülent Ecevit Üniversitesi, İktisadi ve İdari Bilimler Fakültesi, Zonguldak, Türkiye Prof. Ahmet Ferda CAKMAK - Bulent Ecevit University, Faculty of Economic \& Administrative Sciences, Zonguldak, Turkey cakmak@beun.edu.tr

Ar. Gör. Mehpare TATLI - Bülent Ecevit Üniversitesi, İktisadi ve İdari Bilimler Fakültesi, Zonguldak, Türkiye

Res. Assist. Mehpare TATLI - Bulent Ecevit University, Faculty of Economic \& Administrative Sciences, Zonguldak, Turkey mehparetatli2013@gmail.com 


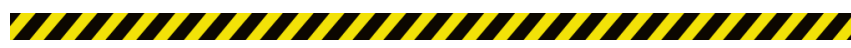

\section{GİRİŞ VE ARAŞTIRMANIN AMACI}

“Güvenlik kültürü” ve "güvenlik iklimi” temalı bilimsel çalışmalarda sektörel farklılıkları göz önünde bulunduran araştırmaların eksikliği ve buna bağlı olarak ölçme materyallerinde evrensel boyutlar belirleme güçlüğü, bilim adamlarınca sık tartışılan konular olmuştur (Glendon ve Litherland, 2001: 157-158) . Farklı örgüt yapıları, iş gereklilikleri, kültürel etkiler gibi pek çok değişkenin etkisi altında bulunan; çalışanların güvenlikle ilgili tutum, davranış ve algılarının inceleme konusu yapıldığı güvenlik kültürü ve güvenlik iklimi çalışmalarında, alanın multidisipliner yapısının göz önünde bulundurulması bir gereklilik olarak karşımıza çıkmaktadır. Araştırmamızda, bu gereklilik referans alınarak; sağlık çalışanlarının karşı karşıya kaldığı riskler, güvenli çalışma ortamı yapılanması ve güvenli davranışlarla ilgili spesifik değerlendirmelere yer verilmiştir. Bu sebeple kullanılan araştırma materyali, sağlık sektörüne özgü önemli verilerin elde edilmesini sağlayacak biçimde düzenlenmiştir.

$\mathrm{Bu}$ çalışmada bir üniversite hastanesinde görev yapan sağlık çalışanlarının iş sağlığı ve güvenliği konusundaki uyumlu davranışları ve güvenlik iklimi algılarının birbirleri ile ilişki ve farklılıklarının incelenmesi amaçlanmaktadır. Araştırmada, sağlık, yönetim, insan kaynakları ve davranış bilimleri bakış açısından eklektik bir yaklaşım ile "güvenlik iklimi” konusunda inceleme ve değerlendirmeler yapılmıştir.

Güvenlik iklimi alanında yapılan pek çok çalışma, bir organizasyondaki güvenlik iklimi algısını oluşturan alt faktörlerin; vaka ve kazalar gibi güvenlikle ilgili sonuçları öngörebileceğini göstermektedir (Zohar, 1980; Brown ve Holmes, 1986; Dedobbeleer ve Beland, 1991; DeJoy, 1994; Niskanen, 1994; Hofmann ve Stetzer, 1996; Akt: Neal vd., 2000:100). Araştırmaların sonuçları; olumlu güvenlik kültürü ve güvenlik ikliminin, çalışma güvenliği ve kaza oranlarının azalması üzerinde pozitif bir etkiye sahip olduğunu göstermektedir (Törner, 2010; Akt: Bergh, 2011, 16). Yapılan araştırma kapsamında bir üniversite hastanesinde çalışmakta olan doktor ve hemşirelerin işyeri güvenlik koşullarıyla ilgili değerlendirmelerini ifade eden güvenlik iklimi algıları ve tedavi-bakım gibi temel sağlık hizmetlerini yerine getirirken iş güvenliği tedbirlerine uyuma davranışları, çalışanların farklı demografik özellikleri ile ilişkileri bakımından çok yönlü olarak incelenmektedir.

\section{GÜVENLİK KÜLTÜRÜ VE GÜVENLİK İKLİMİ}

İş sağlığı ve güvenliği ile ilgili yapılan bilimsel çalışmalarda; "güvenlik kültürü" ve "güvenlik iklimi” üzerinde durulan kavramlar olmuşlardır. Güvenlik kültürü ilk olarak, 1986'daki Çernobil Nükleer Santrali'nde meydana gelen felaket hakkında, 1987 yılında OECD (Organisation for Economic Co-operation and Development) Nükleer Ajansı Raporu'nda kullanılan bir kavramdır (INSAG, 1988). Bu rapor, örgütsel hataların ve iş görenlerin kural tanımaz davranışlarının, felaketin yaşanmasında oynadı̆̆ı role işaret etmektedir (Cooper, 2000: 113). IAEA (The International Atomic Energy Authority) 1991 yılında Güvenlik kültürünü, "Kurumun sağlık ve güvenlik programlarının yeterliliğine, tarzına ve uygulamadaki ısrarına karar veren birey ve grupların değer, tutum, yetkinlik ve davranış örüntülerinin bir ürünüdür" ifadeleri ile tanımlamıştır (IAEA, 1991; Akt: Özkan ve Lajunen, 2003: 3). İngiliz Endüstri Konfederasyonu (CBI, 1991) ise güvenlik kültürünü, risk, kaza ve hastalıklar hakkında bir organizasyonun bütün üyeleri tarafından paylaşılan inançlar ve fikirler olarak tanımlamaktadır (Cooper, 2000: 114). Turner ve diğerleri (1989) güvenlik kültürünü, daha önceki çalışmalarda yapılan tanımlardan yola çıkarak, geniş bir açıdan ele alarak; "Çalışanların, yöneticilerin, müşterilerin ve kamu üyelerinin maruz kaldıkları tehlike veya zararların minimize edilmesiyle ilgili inançlar, normlar, tutumlar, roller ile sosyal ve teknik uygulamalar kümesi” olarak tanımlamıştır (Akt: Cox ve Flin, 1998: 191).

Araştırmacıların üzerinde durduğu bir diğer konu olarak güvenlik iklimi alanında yapılan çalışmalarda, kavram ile ilgili pek çok açıklama getirilmiş olması ile birlikte, yapılan tanımlar, araştırmacıların konuyu ele alış biçimlerine göre farklılaşmaktadır. İlk olarak Zohar tarafından 1980 yılında literatüre kazandırılan "güvenlik iklimi” kavramı; organizasyonel iklimin özel bir türü olarak kabul edilmiş ve organizasyonun güvenlik bakış açısıyla ilgili, çalışanlar tarafından algılanan bilgi bütünü olarak tanımlanmıştır (Zohar, 1980: 96). Güvenlikle ilgili bu betimleyici algıların, bir organizasyonda üretim gibi diğer öncelikleri de dikkate alarak, gerçek güvenlik öncelikleri (priority of safety) için bir gösterge oluşturduğu üzerinde durulmaktadır (Zohar, 2000; Akt: Cooper ve Phillips, 2004: 497;).

Güvenlik iklimi, güvenlik kültürünün bir alt bileşeni olarak kabul edilmektedir (International Atomic Energy Agency [IAEA], 1988; Akt: Cooper ve Phillips, 2004: 497). Neal, Griffin, Hart, (2000) Güvenlik ikliminin önemli bileşenleri olarak bir çok faktör olduğunu belirtmiş, bunlardan en önemli olanlarını şöyle sıralamışlardır: yönetim değerleri, yönetim uygulamaları, iletişimin kalitesi ve işyeri sağlığı ve güvenliği konularına çalışanların katılımı (Neal vd., 2000: 100). Güvenlik iklimi alanında yapılan bir dizi çalışma, bu faktörlerin; vaka ve kazalar gibi, güvenlik ile ilgili sonuçları öngördüğünü göstermektedir (Zohar, 1980; Brown ve Holmes, 1986; Dedobbeleer ve Beland, 1991; DeJoy, 1994; Niskanen, 1994; Hofmann ve Stetzer, 1996; Akt: Neal vd., 2000: 100). 
Griffin ve Neal, (2000) 'e göre: güvenlik iklimi organizasyonlarda bireyler tarafından tecrübe edilen iklim tiplerinden biridir (Griffin ve Neal, 2000: 347). Tüm iklim tipleri; bireylerin tecrübelerinden edindikleri algılar ve organizasyonel ödüllere bağlı olarak gelişir ve iklim algısı hiyerarşik bir yapı olarak kavramsallaştırılabilir (Griffin ve Neal, 2000: 347). Bu bağlamda Griffin ve Neal (2000) güvenlik ikliminin; daha spesifik birinci derece faktörlerden oluşan, yüksek dereceli (higher factor) bir iklim boyutu olarak kavramsallaştırılması gerekliliğine vurgu yapmıştır. Birinci derecede güvenlik iklimi faktörlerinin, güvenlik ile ilgili politika, prosedür ve ödüllerin algılanış biçimini yansıtması gerekmektedir (Griffin ve Neal, 2000: 348). Güvenlik ikliminin daha yüksek dereceli faktörü; çalışanların organizasyonları ile ilgili değerlendirmeleri sonucunda vardıkları, organizasyonun ne ölçüde güvenli olduğuna dair inançlarını yansıtmalıdır (Griffin ve Neal: 2000: 348).

Wiegmann vd. (2002) araştırmalarında; güvenlik iklimi terimine ilişkin farklı yazarlar ve kuruluşlar tarafından yapılan tanımların detaylı bir incelemesini yaparak, önceki açıklamaların ortak noktalarından hareketle güvenlik iklimi konusunda genel bir tanımlama yapmışlardır. Buna göre güvenlik iklimi: organizasyondaki bireylerin anlayışlarındaki benzerliklere bağlı geçici bir güvenlik kültürü ölçümüdür. Bu sebeple, koşullara bağlı bir yapıya sahiptir, belli bir zaman diliminde ve belli bir yerde güvenliğin algılanış biçimidir. Koşullar ve çevresel etkenlerdeki değişimlere bağlı olarak değişmeye meyillidir açıklamaları getirilmiştir (Wiegmann vd., 2002: 10).

"Güvenlik kültürü" ve "güvenlik iklimi" kavramları tanımlanış biçimleri bakımından benzerlikler içerse de, yapılan tanımlar incelendiğinde; güvenlik kültürü işyerinde güvenlik koşulları ile ilgili, çok daha uzun bir zaman dilimine yayılmış, örgüt kültürünün bir parçası haline gelmiş tutum, davranış, algılar bütününden oluşan geniş bir anlam ifade etmektedir. Güvenlik iklimi ise, işyeri güvenliği ile ilgili var olan durumun, örgüt tarafından kısa periyotlar için algılanma biçimidir. Guldenmund (2000) güvenlik kültürü ile ilgili çalışmasında 16 farklı araştırmacının güvenlik kültürü ve güvenlik iklimi tanımlarını çeşitli yönleri ile değerlendirmeye tabi tutmuş ve ilgili kavramları birbirinden farklılaştırmıştır. Buna göre; "güvenlik iklimi çalışanların işletmedeki güvenliğe ilişkin algılamalarından, güvenlik kültürü ise çalışanların çevreleriyle olan ilişkilerinden ve gerçeklerden oluşmaktadır" (Guldenmund 2000:215-257; Akt: Tüzüner ve Özaslan, 2011: 142).

Güvenlik iklimi alanında yapılan bilimsel çalışmalarda, işyeri güvenlik koşullarının örgüt üyeleri tarafından değerlendirilmesi üzerinde etkili olan faktörler ve güvenlik konusunda paylaşılan algıların doğru biçimde nasıl ölçüleceği, ön plana çıktığı görülen konulardır. İşletmelerde yöneti- min izlediği güvenlik politika ve uygulamaları ile çalışanların güvenlik gereklilikleri konusundaki uyumlu davranışla$\mathrm{r} 1$, işyeri güvenliği hakkındaki genel anlayışı etkileyen önemli boyutlar olarak kabul edilmiştir. Pek çok araştırmanın sonuçları göstermektedir ki; olumlu güvenlik kültürü ve güvenlik iklimi, çalışma güvenliği ve kaza oranlarının azalması üzerinde pozitif bir etkiye sahiptir (Törner, 2010; Akt: Bergh, 2011, 16). Bunun yanında olumlu güvenlik kültürü, üretkenliğin artması ve uzun zamanda maliyetlerin azalmasına da önemli ölçüde katkı sağlamaktadır (Hudson, 1999; Akt: Bergh, 2011, 16).

\section{SAĞLIK SEKTÖRÜNDE İŞ KAZASI RİSKLERİ VE GÜVENLİK İKLİMİ}

Bireylere sağlanan doğrudan ve dolaylı sağlık hizmetlerinin yerine getirildiği sağlık bakım hizmetleri; hastaneler, klinikler, diş hekimliği ofisleri, tıp merkezleri, acil servisler, evde bakım hizmetleri vb. pek çok alanda yürütülen faaliyetleri kapsamaktadır. Çalışanlarının yaklaşık \%10’u sağlık ve sosyal yardım sektöründe görev yapan ve bunların birçoğu da hastanelerde çalışmakta olan Avrupa' da iş kazalarının en sık gerçekleştiği sektörlerden biri sağlı sektörüdür (European Commision, 2014: 9, 51).

Sağlık çalışanlarının karşı karşıya kaldığı sağlık ve güvenlik tehlikeleri arasında; kan yolu ile bulaşan patojenler ve biyolojik tehlikeler, çeşitli kimyasal-ilaç ve anestezik gaz maruziyetleri, solunum yolu ile bulaşan patojenler, kas ve iskelet sistemi travmaları ve bozuklukları, işyeri şiddeti, radyoaktif madde ve $\mathrm{x}$-ray maruziyeti, laboratuvar ve benzeri alanlarda çalışmaktan kaynaklanan bulaşıcı tehlikeler gibi pek çok önemli risk faktörü yer almaktadır (O.S.H.A., TY). Türkiye'de yürütülen araştırmalarda hemşirelerin en sık karşılaştığı iş güvenliği tehdidinin kesici delici alet yaralanmaları ve vücut sıvılarına maruz kalmaktan kaynaklanan bulaşıcı riskler olduğu belirtilmektedir (Saygun, 2012: 377).

Hastanelerde çalışmakta olan sağlık çalışanları; bulaşıcı hastalık riski taşıyan, artan hasta devir oranı ve hasta yaygınlığının bulunduğu bir ortamda her zamankinden daha ağır koşullarda, daha hızlı çalışmak zorunda kalmakta ve güvenlik eğitimi programları için daha az zamana sahip olmaktadırlar (Gershon vd., 2000: 212-213). Gershon ve diğerleri (2000), hastane çalışanlarının güvenlik ile ilgili algılarının, hastane güvenlik programlarının dizayn edilmesi ve güncelleştirilmesi sırasında nadiren resmi olarak göz önünde bulundurulduğunu ya da değerlendirildiğini belirtmektedirler (Gershon vd., 2000: 212).

Sonuçları ne olursa olsun kazalara maruz kalma olayları, çalışanlar ve dahası organizasyonlar için oldukça külfetli olabileceğinden; güvenlik iklimi algısının geliştirmenin 
zamana yayılan anlamlı sonuçları olabilmektedir (Gershon vd., 2000: 212). Gerçekleştirilen birçok araştırmanın sonuçları; olumlu güvenlik kültürü ve güvenlik ikliminin, çalışma güvenliği ve kaza oranlarının azalması üzerinde pozitif bir etkiye sahip olduğunu göstermektedir (Törner, 2010; Akt: Bergh, 2011: 16). Bunun yanında olumlu güvenlik kültürü, üretkenliğin artması ve uzun zamanda maliyetlerin azalmasına da önemli ölçüde katkı sağlamaktadır (Hudson, 1999; Akt: Bergh, 2011: 16)

$\mathrm{Bu}$ çalışma kapsamında kullanılan anket formunun seçimi ve uyarlaması yapılırken araştırma örneklemini oluşturan sağlık çalışanlarının icra etmekte oldukları iş ve görevin yapısal unsurları göz önünde bulundurulmuştur. Kurumda çalışmakta olan hemşire ve doktorların sık karşılaştıkları iş kazası grubunun kan yolu ile bulaşan patojen risk içeren iş kazaları olduğu bilgisinden hareket edilerek (European Commision, 2014: 30), hastane çalışanlarının kan yolu ile bulaşan iş kazaları bağlamında güvenlik iklimi algılarını ölçümleme yoluna gidilmiştir.

\section{METODOLOJİ}

\section{A. Araştırma Deseni ve Hipotezleri}

$\mathrm{Bu}$ çalışma kapsamında katılımcılıların; demografik bilgileri, iş sağlığı ve güvenliği konusundaki uyumlu davranışları ve güvenlik iklimi algılarının birbirleri ile ilişki ve farklılıklarının incelendiği bir araştırma modeli tasarlanmıştır. Yapılan araştırmada demografik değişkenler, çalışanların güvenlik tedbirlerinde uyma davranışları ve güvenlik iklimi algıları arasında kurulan hipotezler aşağıdaki gibidir:

H 1: Çalışanların meslekteki tecrübeleri ile güvenlik tedbirlerinde uyumlu davranışları, ortalama güvenlik iklimi algıları ve güvenlik iklimi faktörleri arasında bir ilişki vardir.

H 2: Farklı meslek çalışanlarının güvenlik iklimi algıları ve güvenlik tedbirlerinde uyma davranışları farklılık göstermektedir.

H 3: Ameliyathane hemşireleri ile diğer birimlerde çalışmakta olan hemşireler için, güvenlik iklimi algıları ve güvenlik tedbirlerinde uyma davranışları farklılık göstermektedir.

H 4: Daha önce yöneticilik görevi yerine getirmiş olan katılımcılar ile diğer katılımcılar için, güvenlik iklimi algıları ve güvenlik tedbirlerinde uyma davranışları farklılık göstermektedir.

\section{B. Araştırma Materyali ve Uygulama}

Araştırma materyalinin seçimi ve uyarlaması yapılma- dan önce, sağlık kurumlarında koruyucu önlemler ve sağlık çalışanlarının maruz kaldıkları risk faktörleri incelenmiş, hastanelerde çalışan sağllk personeli için (hemşire ve doktorlar) özel risk değerlendirmeleri sonucunda en sık karşılaşılan risk grubunun "biyolojik ajanlar" olduğu bulgusundan hareket edilmiştir (European Commision, 2014: 30). Araştırma amacı ve hipotezleri doğrultusunda, kan yolu ile bulaşan patojen risk içeren iş kazalarına maruz kalma potansiyeli yüksek olan sağlık çalışanları araştırma kapsamına alınmıştır.

Endüstriyel ortamda çalışanların organizasyonları ile bağlantılı güvenlik iklimi algıları, işyeri yaralanma oranları ve güvenli işyeri uygulamalarının önemli farklılıklarını gösteren çalışmaların yapıldığını belirten Gershon ve diğerleri (2000) hastane ortamı için özel güvenlik gereksinimlerini değerlendirmeye yönelik ölçüm araçlarının nadiren geliştirildiğini belirtmiştir (Gershon vd.,2000: 211). Bu gereklilik üzerine; kurumsal bağlılık açısından, kan yoluyla bulaşan patojen risk yönetimi programlarına göre; güvenli işyeri uygulamaları konusunda çalışanların tutumları ve güvenlik iklimi algıları arasındaki ilişkiyi değerlendiren, kısa ve etkili bir hastane güvenlik iklimi anketi geliştirmişlerdir (Gershon vd., 2000: 221).

Gershon ve diğerleri (2000) tarafından, hastane çalışanları için geliştirilen; kan yolu ile bulaşan patojen risklere maruz kalma, güvenli davranışlara uyma ve çalışanların hastane güvenlik iklimi algılarının değerlendirilmesinde kullanılan 20 ifadelik anket formu, Bülent Ecevit Üniversitesi Sağlık Uygulama ve Araştırma Merkezi'nde çalışmakta olan sağlık çalışanları ile gerçekleştirilen ön çalışma sonuçlarına göre revize edilerek uygulanmıştır.

Sağlık çalışanlarının güvenlik tedbirlerine uyumlu davranışlarını ölçmek için ise, Gershon vd. (2000) tarafından geliştirilen on dört ifadeli "Güvenli Davranışlara Uyum Ölçeği”, aynı yöntem izlenerek kurumun güvenlik donanımları ve yapılanması doğrultusunda uyarlanarak uygulanmıştır. Ön çalışmada; görüşme ve bilgi toplama yoluyla sektörün ve kurumun yapısal farklılıklarının yanında, kültürel etkiler de göz önünde bulundurulmuş ve ölçekler üzerinde gerekli uyarlamalar yapılmıştır.

Araştırmada kullanılan kontrol değişkenlerinin ölçülmesi için; katılımcıların yaşı, cinsiyeti, eğitim düzeyi, meslekteki tecrübesi, kurumdaki görevi (doktor ve hemşire), haftalık çalışma biçimi (nöbetli, gündüz mesaili) daha önce herhangi bir yönetim görevi yerine getirip getirmedikleri sorulmuştur. Ayrıca hemşireler için çalışmakta oldukları birimin hangi kategoriye (ameliyathane hemşiresi, yoğun bakım hemşiresi, servis hemşiresi, poliklinik/gündüz tedavi hemşiresi ve diğer) dâhil olduğu bilgisine yer verilmiştir.

Araştırma örnekleminde yer alan, Bülent Ecevit Üni- 
versitesi Sağlık Uygulama ve Araştırma Merkezinde çalışmakta olanda hemşireler ile araştırma görevlisi ve intörn doktorlardan oluşan sağllk sektörü çalışanlarına 250 anket formu dağıtılmış bunların 192 'si değerlendirmeye alınmıştır. $\% 76,8$ cevaplanma oranıyla, 149 'u hemşire, 43 'ü intörn ve araştırma görevlisi doktorlardan oluşan toplam 192 kişilik örneklem grubu ile analizler gerçekleştirilmiştir.

Araştırmada toplanan veriler SPSS Statistics 19 programında analiz edilmiştir. Verilerin analizi için; frekans dağılımı, güvenirlik analizi, faktör analizi, t testi, Ki-Kare testi ve korelasyon analizlerinden faydalanılmışıtır.

\section{BULGULAR}

\section{A. Demografik Bulgular}

Tablo 1: Demografik Bulgular

\begin{tabular}{|c|c|c|}
\hline $\begin{array}{l}\text { Değişken } \\
\text { Cinsiyet }\end{array}$ & $\mathbf{N}$ & $\%$ \\
\hline Kadın & 142 & 74,0 \\
\hline Erkek & 50 & 26,0 \\
\hline \multicolumn{3}{|l|}{ Kurumdaki Görev } \\
\hline Hemşire & 149 & 77,6 \\
\hline Doktor & 43 & 22,4 \\
\hline \multicolumn{3}{|l|}{ Eğitim Düzeyi } \\
\hline Sağlık Meslek Lisesi & 18 & 9,4 \\
\hline Tıp F. Mezunu/Öğrencisi & 43 & 22,4 \\
\hline Lise & 3 & 1,6 \\
\hline Ön Lisans & 15 & 7,8 \\
\hline Lisans & 98 & 51,0 \\
\hline Yüksek Lisans & 15 & 7,8 \\
\hline \multicolumn{3}{|l|}{ Haftalık Çalışma Biçimi } \\
\hline Gündüz Mesaili & 66 & 34,4 \\
\hline Nöbetli/Vardiyalı & 126 & 65,6 \\
\hline \multicolumn{3}{|l|}{ Yöneticilik Görevi } \\
\hline Var & 56 & 29,2 \\
\hline Yok & 136 & 70,8 \\
\hline Yaş & Ortalama & Std.Sapma \\
\hline Hemşire ( $n=149)$ & 32,39 & 4,79 \\
\hline Doktor $(n=43)$ & 28,20 & 3,35 \\
\hline Tüm Örneklem (n=192) & 31,45 & 4,85 \\
\hline \multicolumn{3}{|l|}{ Toplam Çalışma Süreleri } \\
\hline Hemşire ( $n=149)$ & 9,81 & 4,82 \\
\hline Doktor $(n=43)$ & 3,65 & 2,74 \\
\hline Tüm Örneklem (n=192) & 8,34 & 5,18 \\
\hline
\end{tabular}

Araşıtırmada kullanılan ankette katılımcılara; cinsiyet, yaş, eğitim düzeyi, iş tecrübesi, kurumdaki çalışma yıll, görev, haftalık çalışma biçimi, daha evvel yerine getirilen yöneticilik görevi ve hemşireler için ameliyathane, yoğun bakım, servis, poliklinik/gündüz tedavi ve diğer olmak üzere çalışmakta oldukları birimle ilgili kategorik seçeneklerden oluşan sorular sorulmuştur. Toplanan verilere ilişkin elde edilen dağılımlar tablo 1'de verilmiştir. Araştırma örneklemi 142 kadın, 50 erkek olmak üzere sağlık sektöründe çalışan, büyük çoğunluğu (\%74) kadın olan, hemşire ve doktorlardan oluşmaktadır.
Kurumda çalışmakta olan intörn ve araştırma görevlisi doktorlar "Tıp Fakültesi Mezunu ve Öğrencisi” eğitim düzeyinde iken; hemşirelerin eğitim düzeylerine göre dağılımları "Sağlık Meslek Lisesi", "Lise", "Ön Lisans", "Lisans" ve "Yüksek Lisans" olmak üzere farklılık göstermektedir. Buna göre katılımcıların; \%51'i lisans, \%22,4’ü tıp fakültesi mezunu/öğrencisi, $\% 9,4$ 'ü sağlık meslek lisesi, $\% 7,8$ 'i ön lisans, \%7,8'i yüksek lisans, \%1,6'sı lise düzeyinde eğitim görmüştür. Çalış̧anlarının büyük çoğunluğu nöbetli çalışanlardan oluşan bir sağlık kuruluşunda yürütülen araştırmada katılımcıların da büyük çoğunluğu nöbetli sağlık çalışanlarından meydana gelmektedir. Buna göre araşıırma örnekleminin $\% 65,6$ 'sı nöbetli/vardiyalı çalışanlardir.

Katılımcıların kurumda daha evvel herhangi bir yöneticilik görevi veya komisyon/komite üyeliği görevi yerine getirmeleri durumunda, söz konusu pozisyonların belirtildiği kutuları işaretlemeleri istenmiştir. Böylece katılımcılarla ilgili daha evvel bir yöneticilik görevi yapıp yapmadıkları verisinin elde edilmesi ve bu verinin katılımciların uyum davranışı ve güvenlik iklimi algısı ile ilişkisinin incelenmesi amaçlanmıştır.

Araştırmaya katılan 192 kişiden 56'sı çalıştığı kurumda bir yöneticilik görevi yerine getirmiştir. Bunlardan; başhemşire yardımcılığı (3), supervisor/gözetmenlik (7), sorumlu hemşirelik (33), başasistanlık (4), komisyon komite üyeliği (20) olmak üzere 5 tür yönetim veya denetim görevinden, bir veya birkaçını üstlenmiş olan katılımcılar araştırma örnekleminin \%29,2'sini oluşturmaktadır.

Mesleği hemşirelik olan katılımcıların kurumda çalışmakta oldukları birimler arasında iş sağlı̆ı ve güvenliği açısından kan yolu ile bulaşan patojen risk seviyelerinde farklılıklar olabileceği düşünülerek; ameliyathane, yoğun bakım, servis, poliklinik/gündüz tedavi ve diğer olmak üzere ayrılmış ve hemşireler birimlere göre kategorize edilmiştir.

Tablo 2: Hemşirelerin Birimlere Göre Dağılımı

\begin{tabular}{lcc}
\hline Birim & N & $\%$ \\
\hline Ameliyathane & 21 & 14,1 \\
Yoğun Bakım & 32 & 21,5 \\
Servis & 71 & 47,7 \\
Poliklinik/Gündüz Tedavi & 18 & 12,1 \\
Diğer & 7 & 4,7 \\
\hline Toplam & 149 & 100 \\
\hline
\end{tabular}

$\mathrm{Bu}$ kategorileşmeye doktorlar dâhil edilmemiștir. Bu durumun nedeni doktorların çalışmakta oldukları birimlerin iş sağlığı ve güvenliği riskleri açısından değerlendirildiğinde daha farklı bir yapı ortaya çıkmasıdır. Örnek vermek gerekirse cerrahi serviste araştırma görevlisi olarak çalışmakta olan bir doktor haftanın belirli günleri ameliyatha- 
nede görev alırken diğer günlerde poliklinik hizmeti yerine getirmekte, aynı zamanda serviste nöbetçi olarak görevlendirilebilmektedir. Dolayısıyla böyle bir ayrımın doktorlar için yapılabilmesi, doktorlar tarafından kurumda yerine getirilen işin yapısı için uygun değildir. Tablo 2'ye göre ankete katılan 149 hemşirenin \%14,1'i (N=21) ameliyathanede, \%21,5'i $(\mathrm{N}=32)$ yoğun bakımda, \%47,7'si $(\mathrm{N}=71)$ serviste, $\% 12,1$ 'i $(\mathrm{N}=18)$ poliklinik/gündüz tedavi hizmetinde, \%4,7’si $(\mathrm{N}=7)$ diğer grupta yer almaktadır.

\section{B. Ölçekler için Güvenirlik ve Faktör Analizi Sonuçları}

Araştırmada kullanılan anket formu üç kısımdan oluşmaktadır. Birinci kısımda çalışanlarla ilgili demografik bilgileri sağlamaya yönelik sorular yer almaktadır. İkinci kısım, çalışanların iş sağlığı ve güvenliği konusunda gösterdiği uyumlu davranışların on dört soruluk likert tipi ölçek kullanılarak ölçümlendiği kısımdır. Anket formunun yirmi sorudan oluşan son kısmı ise çalışanların güvenlik iklimi algılarının altı boyutta ölçümlendiği üçüncü kısımdır.

Uyumlu davranışları ölçülmesinde kullanılan, 14 ifadeyi içeren ölçeğin güvenilirlik analizi sonucu ortaya çıkan Cronbach alpha değeri ,798 olarak hesaplanmıştır. Araştırma kapsamında güvenlik iklimi algısını ölçmek amacı ile kültürel uyarlaması yapılan 20 ifadeli "Hastane Güvenlik İklimi Anketi” güvenilirlik ve faktör analizine tabi tutulmuş, anket formunun asıl örneği ile örtüşen 6 faktör yapısı elde edilmiştir. Ölçeğin Cronbach alpha değerinin, faktörler bazında ,75 ile ,90 arasında değiştiği ve sosyal bilimlerde kabul edilen sınırlar içerisinde olduğu bulunmuştur (Sekaran, 2003:311). Ölçeğin tamamı için hesaplanan güvenilirlik katsayısı ise ,926 olarak bulunmuştur.

Faktör analizi sonuçlarına göre, faktörlerin çalışanlarca algılanan güvenlik iklimini açıklama oranı \%74,278 bulunmuştur. Söz konusu faktörler sırası ile; G1-F1: iş yükü ve bireysel yetkinlik, G1-F2: yönetimin desteği, G1-F3:

Tablo 3: Güvenlik İklimi Algısı Ölçeği Faktör Analizi Sonuçları

\begin{tabular}{|c|c|c|c|}
\hline & $\begin{array}{l}\text { Faktör } \\
\text { Yükleri }\end{array}$ & $\begin{array}{c}\text { Açıklanan } \\
\text { varyans } \\
\text { \%'si }\end{array}$ & $\begin{array}{c}\text { Cronbach } \\
\text { alpha } \\
\text { değeri }\end{array}$ \\
\hline \multicolumn{4}{|l|}{ G1-F1: İş Yükü ve Bireysel Yetkinlik } \\
\hline İşimde, güvenliğim ile ilgili kişisel koruyucu önlemleri alabilmek için daima yeterli zamana sahibim. & 870 & \multirow{4}{*}{15,847} & \multirow{4}{*}{,886 } \\
\hline $\begin{array}{l}\text { Benim iş yüküm, çalışma güvenliğim için gerekli olan kişisel koruyucu önlemleri almama genellikle engel } \\
\text { olmaz }\end{array}$ & ,826 & & \\
\hline $\begin{array}{l}\text { Kişisel koruyucu önlemleri almak, benim iş yoğunluğumu çok fazla artırmadığı için, bu önlemleri genel- } \\
\text { likle alabilirim }\end{array}$ & ,825 & & \\
\hline $\begin{array}{l}\text { Uygun biçimden aldığım eğitim ve gerekli ekipmana sahip olduğumdan, kendimi kan yolu ile bulaşan } \\
\text { hastalıklara karşı koruyabilme şansına sahibim }\end{array}$ & ,579 & & \\
\hline \multicolumn{4}{|l|}{ G1-F2: Yönetimin Desteği } \\
\hline $\begin{array}{l}\text { Çalışma ünitemizde tehlikeli işler ve prosedürler uygulanırken, tehlikeyi en aza indirgemek için tüm } \\
\text { makul adımlar atılır }\end{array}$ & ,796 & \multirow{4}{*}{13,842} & \multirow{4}{*}{,866 } \\
\hline $\begin{array}{l}\text { Çalışanların kan yolu ile bulaşan hastalıklardan korunması için gereken önlemlerin alınması, amirlerimiz } \\
\text { için yüksek bir önceliğe sahiptir }\end{array}$ & ,748 & & \\
\hline Çalışanlar iş sağlığı ve güvenliği konularında aktif olmaya teşvik edilmektedir & ,700 & & \\
\hline $\begin{array}{l}\text { Ünitemizdeki yöneticiler, çalışanların kan yolu ile bulaşan hastalıklardan korunması için, üzerlerine düşe- } \\
\text { ni yapar }\end{array}$ & ,688 & & \\
\hline \multicolumn{4}{|l|}{ G1-F3: İletişim ve Kişilerarası İlişkiler } \\
\hline Benim birimimin üyeleri birbirini çalışma yaşamında destekler & 867 & \multirow{4}{*}{12,829} & \multirow{4}{*}{,822 } \\
\hline Benim birimimde anlaşmazlıklar en az düzeydedir &, 804 & & \\
\hline Çalıştı̆̆ım birimde, yöneticiler ve personel arasında açık bir iletişim vardır & ,682 & & \\
\hline Çalışma alanımız kalabalık değildir & ,448 & & \\
\hline \multicolumn{4}{|l|}{ G1-F4: Kontrol, Eğitim ve Geribildirim } \\
\hline $\begin{array}{l}\text { Bizim ünitemizde güvensiz iş uygulamaları supervisor (gözetmen) tarafindan uyarılır. (hekimler ve intörn- } \\
\text { ler için, birim hocaları v.b. yetkililer tarafindan) }\end{array}$ & ,786 & \multirow{4}{*}{12,632} & \multirow{4}{*}{,778 } \\
\hline $\begin{array}{l}\text { Hemşirelik hizmetleri /yöneticiler sık sık güvenli çalışma uygulamalarını bizlerle görüşür. (hekimler ve } \\
\text { intörnler için, birim hocaları v.b. yetkililer) }\end{array}$ & ,782 & & \\
\hline Bizim ünitemizde enfeksiyon kontrol ve önleme kitapçığının bir kopyası mevcuttur & ,585 & & \\
\hline Çalışanlar iş yerindeki potansiyel sağılı tehlikelerinin farkında olması için eğitilmiştir & ,508 & & \\
\hline \multicolumn{4}{|l|}{ G1-F5: Temizlik ve Düzen } \\
\hline Çalışma alanımız dağınık değildir & ,839 & \multirow{2}{*}{9,739} & \multirow{2}{*}{899} \\
\hline Çalışma alanımız temiz tutulur & ,819 & & \\
\hline \multicolumn{4}{|l|}{ G1-F6: Ekipmanların Ulaşılabilirliği } \\
\hline Çalışma alanımızda keskin kapları kolay erişilebilir yerdedir & ,843 & \multirow{2}{*}{9,388} & \multirow{2}{*}{ 753 } \\
\hline Çalışma alanımızda tek kullanımlık eldivenlere kolaylıkla erişilebilir & ,835 & & \\
\hline Toplam Varyans: 74,278 & & & \\
\hline
\end{tabular}


Tablo 4: Tecrübe, Güvenlik İklimi, Güvenlik İklimi Boyutları ve Uyma Davranışı İçin Korelasyon Analizi Sonuçları

\begin{tabular}{|c|c|c|c|c|c|c|c|c|c|}
\hline \multirow{2}{*}{\begin{tabular}{|l} 
Tecrübe \\
\end{tabular}} & Tecrübe & G1_F1 & G1_F2 & G1_F3 & G1_F4 & G1_F5 & G1_F6 & Güvenlik İklimi & Uyma Davranışı \\
\hline & & & & & & & & & \\
\hline G1_F1 &, $392^{* *}$ & & & & & & & & \\
\hline G1_F2 &, $279^{* *}$ &, $372^{* *}$ & - & & & & & & \\
\hline G1_F3 & $240^{* *}$ & $297^{* *}$ &, $585^{*}$ & - & & & & & \\
\hline G1_F4 &, $337^{* *}$ & $345^{* *}$ & $624^{* *}$ &, $568^{* *}$ & & & & & \\
\hline G1_F5 &, $282^{* *}$ & $430^{* *}$ &, $572^{* *}$ & $441^{* *}$ &, $587^{* *}$ & & & & \\
\hline G1_F6 &, $265^{* *}$ & $263^{* *}$ & $498^{* *}$ & $442^{* *}$ &, $518^{* *}$ &, $601^{* *}$ & 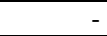 & & \\
\hline Güvenlik İklimi & $377^{* *}$ &, $503^{* *}$ & $830^{* *}$ &, $761^{* *}$ & $852^{* *}$ &, $786^{* *}$ &, $732^{* *}$ & - & \\
\hline Uyma Davranışı & $255^{* *}$ & $359^{* *}$ & $453^{* *}$ & $391^{* *}$ &, $373^{* *}$ &, $250^{* * *}$ & $195^{* *}$ & ,444 $4^{* *}$ & \\
\hline
\end{tabular}

**. Correlation is significant at the 0.01 level (2-tailed).

G1_F1: İ̧ yükü ve bireysel yetkinlik

G1_F2: Yönetimin desteği

G1_F3: Iletişim ve kişilerarası ilişkiler

G1_F4: Kontrol/eğitim ve geribildirim

G1 F5: Temizlik ve düzen

G1_F6: Ekipmanların ulaşılabilirliği

iletişim ve kişiler arası ilişkiler, G1-F4: kontrol, eğitim ve geribildirim, G1-F5: temizlik ve düzen, G1-F6: ekipmanların ulaşılabilirliği olarak ifade edilmiştir.

C. Demografik Veriler, Güvenlik Tedbirlerine Uyma Davranışı ve Güvenlik İklimi Algısı Arasındaki İlişkilere Dair Bulgular

Veriler üzerindeki analizler gerçekleştirilirken istatistiki hesaplamalar, katılımcıların güvenlik tedbirlerine uyma davranışlarına ve güvenlik iklimi algılarına ilişkin ortalama değerler üzerinden yapılmıştır. Aynı şekilde her bir güvenlik iklimi faktör yapısına ilişkin ortalama değerler analizlerde kullanılmıştır. Anket formunda katılımcıların mesleki tecrübesini yıl ve ay cinsinde ifade etmeleri istenmiş, verinin SPSS ortamına girişi de sayısal değer olarak gerçekleştirilmiştir.

Katılımcıların meslekteki tecrübeleri, uyma davranışı, güvenlik iklimi faktörleri ve güvenlik iklimi ortalama değerlerinin birbirleri ile ilişkisini incelemek için korelasyon analizinden faydalanılmıştır.

Tablo 4'e göre meslekteki toplam tecrübe ile uyumlu davranışlar, güvenlik iklimi boyutları ve ortalama güvenlik iklimi algısı arasında pozitif yönlü anlamlı ilişkilerin varlığı tespit edilmiştir. Bunun yanında Tablo 4'te güvenlik iklimi boyutlarının ve güvenlik iklimi ortalamasının birbirleri ile pozitif yönlü anlamlı ilişki gösterdiği görülmektedir. Ayrıca uyumlu davranışlar ile güvenlik iklimi ve güvenlik iklimi faktörleri arasında da pozitif yönlü ve anlamlı düzeyde ilişki tespit edilmiştir. Buna göre katılımcıların meslekteki toplam tecrübeleri ile çalıştıkları ortamda iş sağlığı ve güvenliği gereklilikleri doğrultusunda uyumlu davranma düzeyi, güvenlik iklimini olumlu algılama seviyesi ve hastane güvenlik iklimini açılayan güvenlik iklimi faktörlerine ilişkin algıları birbirleri ile pozitif yönlü olarak ilişkili bulunmuştur.

Çalışanların güvenlik iklimi algıları ve iş sağlığı ve güvenliği tedbirlerine uyum gösterme davranışları farklı değişkenler açısından analiz edilmiştir. Yapılan analizlerde öncelikle çalışanların kurumdaki görevleri bakımından güvenlik iklimi algıları ve uyumlu davranışları arasında bir farklılık olup olmadığını belirlemek amacıyla bağımsız gruplar t testinden faydalanılmıştır.

Buna göre tablo 5'te görüldüğü üzere hemşire ve doktorların hem güvenlik iklimi algılarında $(\mathrm{p}=0,001)$ hem de uyumlu davranış gösterme düzeylerinde $(\mathrm{p}=0,000)$ anlamlı düzeyde farklılık tespit edilmiştir. Hemşireler çalıştıkları ortamı doktorlara göre daha güvenli algılamakta aynı zamanda daha yüksek uyumlu davranış sergilemektedir.

Çalışmada risk düzeyi bakımından daha yüksek iş kazas1 geçirilmesi olasılığ minde çalışmakta olan hemşirelerin ortalama güvenlik iklimi algıları ve güvenlik iklimi boyutlarıyla ilgili algılarının, diğer hemşirelerden farklı olabileceği düşünülerek bağımsız gruplar $\mathrm{t}$ testi ile ameliyathane hemşireleri ve diğer hemşirelerin güvenlik iklimi algıları arasındaki farklılıklar analiz edilmiştir.

Tablo 6'ya göre ameliyathane hemşireleri ve diğer hem-

Tablo 5: Hemşire ve Doktorlar İçin Güvenlik İklimi Algısı ve Uyma Davranışı Grup İstatistikleri ve Bağımsız Gruplar T Testi Sonuçları

\begin{tabular}{|l|l|c|c|c|c|c|}
\hline \multicolumn{2}{|l|}{ Kurumdaki Görev } & $\mathbf{N}$ & Ortalama & Standart Sapma & $\mathbf{t}$ & $\mathbf{p}$ \\
\hline \multirow{2}{*}{$\begin{array}{l}\text { Güvenlik iklimi } \\
\text { Algısı }\end{array}$} & Hemşire & 149 & 3,7662 & 0,6628 & \multirow{2}{*}{3,438} & \\
\cline { 2 - 6 } & Doktor & 43 & 3,3846 & 0,55896 & \\
\hline \multirow{2}{*}{ Uyma Davranışı } & Hemşire & 149 & 4,3701 & 0,47559 & & \multirow{2}{*}{4,332} \\
\cline { 2 - 5 } & Doktor & 43 & 3,9395 & 0,5997 & 0,000 \\
\hline
\end{tabular}


Tablo 6: Ameliyathane Hemşireleri ve Diğer Hemşirelerin Güvenlik İklimi Algısı ve Güvenlik İklimi Boyutları İçin Grup İstatistikleri ve Bağımsız Gruplar t Testi Analiz Sonuçları

\begin{tabular}{|c|c|c|c|c|c|c|}
\hline D11 & & $n$ & Mean & Std. Deviation & $t$ & $\mathbf{p}$ \\
\hline \multirow{2}{*}{ G1_F1 } & Ameliyathane $\mathrm{H}$. & 21 & 4,4524 & 0,58959 & \multirow{2}{*}{,- 899} & \multirow{2}{*}{ 370 } \\
\hline & Diğer H. & 128 & 4,5664 & 0,53008 & & \\
\hline \multirow{2}{*}{ G1_F2 } & Ameliyathane $\mathrm{H}$. & 21 & 3,9881 & 0,53313 & \multirow{2}{*}{, 530} & \multirow{2}{*}{,599 } \\
\hline & Diğer $\mathrm{H}$. & 128 & 3,9136 & 0,89244 & & \\
\hline \multirow{2}{*}{ G1_F3 } & Ameliyathane $\mathrm{H}$. & 21 & 3,8254 & 0,70411 & \multirow{2}{*}{3,091} & \multirow{2}{*}{,004* } \\
\hline & Diğer $\mathrm{H}$. & 128 & 3,2714 & 1,04393 & & \\
\hline \multirow{2}{*}{ G1_F4 } & Ameliyathane $\mathrm{H}$. & 21 & 3,3773 & 0,75411 & \multirow{2}{*}{$-1,276$} & \multirow{2}{*}{ 204 } \\
\hline & Diğer $\mathrm{H}$. & 128 & 3,6253 & 0,83608 & & \\
\hline \multirow{2}{*}{ G1_F5 } & Ameliyathane $\mathrm{H}$. & 21 & 3,5994 & 0,54725 & \multirow{2}{*}{,- 573} & \multirow{2}{*}{,570 } \\
\hline & Diğer $\mathrm{H}$. & 128 & 3,6814 & 0,89108 & & \\
\hline \multirow{2}{*}{ G1_F6 } & Ameliyathane $\mathrm{H}$. & 21 & 3,7619 & 0,35187 & \multirow{2}{*}{,- 592} & \multirow{2}{*}{,556 } \\
\hline & Diğer H. & 128 & 3,8288 & 0,93786 & & \\
\hline \multirow{2}{*}{ Güvenlik İlimi } & Ameliyathane $\mathrm{H}$. & 21 & 3,7652 & 0,42717 & \multirow{2}{*}{,020 } & \multirow{2}{*}{ 984 } \\
\hline & Diğer H. & 128 & 3,7629 & 0,69355 & & \\
\hline
\end{tabular}

G1_F1: iş̧ükü ve bireysel yetkinlik

G1_F2: Yönetimin desteği

G1_F3: iletişim ve kişilerarası ilişkiler

G1_F4: Kontrol/eğitim ve geribildirim

G1_F5: Temizlik ve düzen

G1_F6: Ekipmanların ulaşılabilirliği

şirelerin güvenlik iklimi algıları arasında yalnızca "İletişim ve kişilerarası ilişkiler” faktörü anlamlı düzeyde farklılık göstermiştir (G1_F3: P=0,004). Gruplar ile ilgili ortalama değerler incelendiğinde ameliyathane hemşirelerinin, "İletişim ve kişilerarası ilişkiler" olarak ifade edilen üçüncü faktörde ortalama değer olarak diğer hemşirelerden daha yüksek bir düzeyi ifade ettiği görülmektedir. Diğer güvenlik iklimi faktörleri ve ortalama güvenlik iklimi algısı iki grup için anlamlı olarak farklı düzeyleri ifade etmemiştir.

Ameliyathane hemşireleri ve diğer birimlerde görev yapan hemşirelerin güvenli davranışlara uyma düzeyleri arasında bir farklılığın bulunup bulunmadığını analiz etmek için yine bağımsız gruplar t testinden faydalanılmıştır. Buna göre; ameliyathane hemşirelerinin diğer hemşirelere göre güvenli davranışlara uyum göstermek bakımında daha yüksek ortalamaya sahip oldukları ve bu farklılığın anlamlı olduğu bulgusuna ulaşılmıştır. Analizler ile ilgili grup istatistiklerini de içeren $t$ testi sonuçları aşağıdaki gibidir:

Tablo 7: Ameliyathane Hemşireleri ve Diğer Hemşirelerin Uyma Davranışı İçin Grup İstatistikleri ve Bağımsız Gruplar t Testi Analiz Sonuçları

\begin{tabular}{|l|l|c|c|c|c|c|}
\hline \multicolumn{2}{|c|}{} & $\mathbf{n}$ & Mean & sd & t & p \\
\hline $\begin{array}{l}\text { Uyma } \\
\text { Davra- } \\
\text { nışı }\end{array}$ & $\begin{array}{l}\text { Ameliyatha- } \\
\text { ne H. }\end{array}$ & 21 & 4,6293 &, 33014 & \multirow{2}{*}{2,794} & \multirow{2}{*}{,006* } \\
\cline { 2 - 6 } & Diğer H. & 128 & 4,3248 &, 48032 & & \\
\hline
\end{tabular}

Çalışanlar kurumda daha önce yöneticilik görevi üstlenmiş olan ve olmayanlar olmak üzere iki gruba ayrılmış- tır. Daha önce yöneticilik yapan ve yapmayan iki grubun, güvenlik iklimi algıları ve uyumlu davranışları arasında bir farklılık olup olmadığını analiz etmek amacıyla bağımsız gruplar $\mathrm{t}$ testinden faydalanılmıştır. Tablo 8 yöneticilik görevi yerine getiren 56 çalışanın güvenlik iklimi algıları ve uyumlu davranış gösterme ortalamalarının, daha önce herhangi bir yöneticilik görevi üstlenmemiş olan çalışanlar ile farklılıklarının düzeyini gösteren grup istatistikleri ve $\mathrm{t}$ testi sonuçlarıdır.

Tablo 8'e göre; uyumlu davranış gösterme iki grup açısından anlamlı düzeyde farklılaşmazken $(\mathrm{p}=0,151>0,05)$, güvenlik iklimi algısı iki grup açısından büyük ölçüde farklılık göstermektedir $(p=0,000<0,05)$. Buna göre, kurumda yöneticilik görevi yerine getirmiş olan çalışanlar tüm güvenlik iklimi faktörleri için anlamlı olarak daha yüksek değerlere sahiptir $(\mathrm{p}=0,003 ; \mathrm{p}=0,001$; $\mathrm{p}=0,022 ; \mathrm{p}=0,003 ; \mathrm{p}=0,005 ; \mathrm{p}=0,000<0,05)$.

\section{SONUÇ}

"Çalışanların meslekteki tecrübeleri ile güvenli davranışlara uyma, ortalama güvenlik iklimi algıları ve güvenlik iklimi faktörleri ile ilgili algıları arasında bir ilişki vardır” olarak ifade edilen araştırma hipotezini test etmek amacıyla korelasyon analizinden faydalanılmıştır. Buna göre meslekteki toplam tecrübe ile uyumlu davranışlar, güvenlik iklimi boyutları ve ortalama güvenlik iklimi algısı arasında pozitif yönlü anlamlı ilişkilerin varlığı tespit edilmiştir. 


\begin{tabular}{|c|c|c|c|c|c|c|}
\hline & Yöneticilik Görevi & n & Ortalama & Standart sapma & $\mathbf{t}$ & p \\
\hline \multirow{2}{*}{ Güvenlik İklimi Algısı } & Hayır & 136 & 3,5625 & 61317 & \multirow{2}{*}{$-4,027$} & \multirow{2}{*}{,000 } \\
\hline & Evet & 56 & 3,9681 & 68377 & & \\
\hline \multirow{2}{*}{ Uyma Davranışı } & Hayır & 136 & 4,2381 & ,53535 & \multirow{2}{*}{$-1,441$} & \multirow{2}{*}{ 151 } \\
\hline & Evet & 56 & 4,3602 & ,53061 & & \\
\hline \multirow{2}{*}{ G1_F1 } & Hayır & 136 & 4,3382 & ,64084 & \multirow{2}{*}{$-2,893$} & \multirow{2}{*}{,004 } \\
\hline & Evet & 56 & 4,6250 & ,58192 & & \\
\hline \multirow{2}{*}{ G1_F2 } & Hayır & 136 & 3,7370 & 81838 & \multirow{2}{*}{$-3,294$} & \multirow{2}{*}{,001 } \\
\hline & Evet & 56 & 4,1641 & ,81223 & & \\
\hline \multirow{2}{*}{ G1_F3 } & Hayır & 136 & 3,1961 & 1,00490 & \multirow{2}{*}{$-2,369$} & \multirow{2}{*}{019} \\
\hline & Evet & 56 & 3,5787 & 1,04709 & & \\
\hline \multirow{2}{*}{ G1_F4 } & Hayır & 136 & 3,3493 & ,73236 & \multirow{2}{*}{$-3,029$} & \multirow{2}{*}{,003 } \\
\hline & Evet & 56 & 3,7725 & 93392 & & \\
\hline \multirow{2}{*}{ G1_F5 } & Hayır & 136 & 3,4767 & ,85040 & \multirow{2}{*}{$-2,815$} & \multirow{2}{*}{,005 } \\
\hline & Evet & 56 & 3,8497 & ,79547 & & \\
\hline \multirow{2}{*}{ G1_F6 } & Hayır & 136 & 3,6200 & 89204 & \multirow{2}{*}{$-3,567$} & \multirow{2}{*}{,000 } \\
\hline & Evet & 56 & 4,1029 & 74702 & & \\
\hline
\end{tabular}

G1_F1: Iş yükü ve bireysel yetkinlik

G1_F2: Yönetimin desteği

G1_F3: iletisim ve kişilerarası iliskiler

G1 F4: Kontrol/eğitim ve geribildirim

G1 F5: Temizlik ve düzen

G1_F6: Ekipmanların ulaşılabilirliği

Bununla birlikte katılımcıların çalıştıkları ortamda iş sağlığı ve güvenliği gereklilikleri doğrultusunda uyumlu davranma düzeyi ile güvenlik iklimini olumlu algılama seviyesi ve hastane güvenlik iklimini açıklayan tüm faktörlere ilişkin algıları (iş yükü ve bireysel yetkinlik, yönetimin desteği, iletişim ve kişilerarası ilişkiler, kontrol/eğitim ve geribildirim, temizlik ve düzen, ekipmanların ulaşılabilirliği) birbirleri ile pozitif yönlü olarak ilişkili bulunmuştur.

Çalışanların kurumdaki görevleri bakımından güvenlik iklimi algıları ve uyumlu davranışları arasında bir farklılık olup olmadığını analiz etmek amacıyla bağımsız gruplar t testinden faydalanılmıştır. Buna göre hemşire ve doktorların hem güvenlik iklimi algılarında hem de uyumlu davranış gösterme düzeylerinde anlamlı farklılık tespit edilmiştir. Hemşireler çalıştıkları ortamı doktorlara göre daha güvenli algılamakta ve daha yüksek uyumlu davranış sergilemektedir. Farklı meslek çalışanlarının güvenli davranışlara uyma ve güvenlik iklimi algı düzeyleri arasında farklılık olacağ yönündeki araştırmanın ikinci hipotezi böylece kabul edilmiştir.

Çalışmada, daha yüksek iş kazası riski barındırması üzerinde durulan ameliyathane biriminde çalışmakta olan hemşirelerin; güvenli davranışlara uyma, ortalama güvenlik iklimi algıları ve güvenlik iklimi boyutlarıyla ilgili algılarının, diğer hemşirelerden farklı olacağı düşünülerek formüle edilen araştırmanın üçüncü hipotezini test etmek amacıyla bağımsız gruplar t testi uygulanmıştır. Yapılan analiz sonucunda; ameliyathane hemşireleri ve diğer hemşirelerin gü- venlik iklimi algıları arasında yalnızca "İletişim ve kişilerarası ilişkiler” faktörü anlamlı düzeyde farklılık göstermiştir. Ameliyathane hemşireleri ve diğer birimlerde görev yapan hemşirelerin güvenli davranışlara uyma düzeyleri arasında bir farklılığın bulunup bulunmadığını analiz etmek için yine bağımsız gruplar $\mathrm{t}$ testinden faydalanılmıştır. Buna göre; ameliyathane hemşirelerinin güvenli davranışlara uyum göstermek konusunda diğer hemşirelere göre daha özenli oldukları $(4,6293>4,3248)$ ve bu farklılığın anlamlı olduğu bulgusuna ulaşılmıştır (tablo 7).

"Daha önce yöneticilik görevi yerine getirmiş olan katılımcılar ile diğer katılımcılar için, güvenlik iklimi algıları ve uyma davranışları arasında bir farklılık vardır.” olarak ifade edilen hipotezin test edilmesi için bağımsız gruplar $\mathrm{t}$ testinden faydalanılmıştır. Analiz sonuçlarına göre; uyumlu davranış gösterme iki grup açısından anlamlı düzeyde farklılaşmazken, güvenlik iklimi algısı iki grup açısından büyük ölçüde farklılık göstermektedir. Kurumda yöneticilik görevi yerine getirmiş olan çalışanların tüm güvenlik iklimi faktörleri için istatistiksel açıdan anlamlı olacak biçimde daha yüksek güvenlik iklimi algısına sahip olduğu görülmüştür (tablo 8).

\section{TARTIŞMA}

Yapılan araştırmada sağlık çalışanlarından oluşan bir örneklem üzerinde çalışanların güvenlik iklimi algıları ve uyma davranışları farklı değişkenler açısından analiz edilmiştir. Öncelikle araştırma örnekleminin sağlık çalışanla- 
rından oluşması sebebiyle, literatür taramaları ile desteklenen "sağlık çalışanlarının en sık maruz kaldıkları iş kazası riskleri” incelenerek araştırma verilerinin kan yolu ile bulaşan patojen riskler üzerinden yapılması, böylece sektöre özgü nitelikli sonuçlara ulaşabileceği düşüncesinden hareket edilmiştir. Araştırmada kullanılan anketler, sektörün iş sağlığı ve güvenliği bakımından diğer sektörlerden ayrılan özellikleri göz önünde bulundurularak yapılan inceleme ve değerlendirmeler sonucunda seçilmiş olup, uygulamanın yapıldığı sağlık kurumu yetkilileri ve çalışanları ile yapılan görüşmeler ile gerekli düzenlemelere tabi tutulmuştur.

Yapılan analizlerden yola çıkılarak, sağlık çalışanlarının güvenlik iklimi algılarının ve güvenli davranışlara uyma düzeylerinin, tecrübe düzeyine bağlı olarak değişiklik gösterdiği yorumu yapılabilir. Araştırma örneklemini oluşturan hemşirelerin, doktorlara göre yaş ve tecrübeleri istatistiksel açıdan anlamlı farklılığı ifade edecek düzeyde daha yüksektir. İki meslek grubunun güvenlik iklimi algıları ve güvenli davranışlara uyum düzeyleri karşılaştırılmış buna göre; hemşirelerin doktorlara göre daha olumlu güvenlik iklimi algısına sahip olduğu, daha yüksek uyma davranışı gösterdiği sonucuna ulaşılmıştır. Elbette ki iki meslek grubunun icra ettikleri iş yapısı, çalışma biçimi, nöbet düzeni, eğitim vb. farklılıklar bu sonuçlar üzerinde etkili olabilecek değişkenlerdir. Ancak yapılan korelasyon analizi sonuçlarına göre sağlık sektörü çalışanlarının tecrübe, ortalama güvenlik iklimi algısı, güvenlik iklimi boyutlarına ilişkin algıları ve uyma davranışı birbirleri ile ilişkili bulunmuştur. Dolayısı ile iki meslek grubunun, iş sağlığı ve güvenliğinde inceleme konusu edinilen değişkenler açısından farklı algı ve davranış düzeylerine sahip olmalarında, "tecrübe" bağımsız değişkeninin etkililiğinden söz etmek yanlış olmayacaktır.

Araştırma formunda, katılımcıların kurumda daha önce yerine getirdikleri yöneticilik görevleri ile ilgili soru ifadesine yer verilmiştir. Kurum yetkilileri ile yapılan görüşmede hastanede çalışmakta olan araştırma görevlisi, intörn doktorlar ve hemşireler tarafından yerine getirilmiş olması muhtemel beş farklı yöneticilik görevi tespit edilmiştir. Katılımcıların hastane güvenlik iklimi algıları ve çalışma gruplarındaki pozisyonları arasındaki muhtemel ilişki ve farklıların analiz edilebilmesi amacıyla; kurumda daha önce yöneticilik görevi üstlenen (grup 1) ve üstlenmeyen (grup 2) çalışanlardan oluşan iki grup için t testi analizleri yapılmıştır. Buna göre grup 1 'de yer alan çalışanların, ortalama güvenlik iklimi ve güvenlik iklimi faktörlerine ilişkin algılarının önemli düzeyde olumlu olduğu sonucuna ulaşılmıştır. Bilindiği üzere algıların oluşumunda pek çok bireysel ve çevresel değişken etkili olabilmektedir. Aynı kurumda çalışan bireylerin yaş, tecrübe, eğitim ve daha birçok farkl1lığı aynı olay veya olguların, çok değişik algılanıp yorumlanabilmesinde etkili olabilmektedir. Bu çalışmada da hasta- ne çalışanlarının güvenlik iklimi algıları üzerinde etkili olan bireysel ve çevresel değişkenlerin varlığı elbette mevcuttur. $\mathrm{Bu}$ araştırma genel olarak görev ve pozisyon olarak birbirine eş düzeyde olan çalışan grupları üzerinde uygulanmıştır. Bununla birlikte hastane bünyesinde yer alan birim, servis ve çalışma gruplarında başasistanlık, sorumlu hemşirelik, gözetmenlik, komisyon komite üyeliği ve başhemşirelikbaşhemşire yardımcılığı olmak üzere yönetim ve denetleme rolü bulunan farklı görevler bazı çalışanlar tarafından halen yerine getirilmektedir, bazı çalışanlar tarafından ise daha evvel yerine getirilmiştir. Araştırmada, Çalışanların kurumda yöneticilik görevi olarak adlandırılan bu görevlerden bir veya bir kaçını yerine getirmiş olmaları halinde, hastane güvenlik iklimiyle ilgili algılarının farklı olabileceği hipotezi geliştirilmiştir. Elde edilen sonuçlara göre, hastanede daha önce bir veya birden fazla yönetim görevi üstlenen çalışanların hastane güvenlik iklimi konusunda daha olumlu algılara sahip olduğu bulgusuna ulaşılmıştır.

\section{KAYNAKÇA}

Bergh, M. (2011). Safety Climate An Evaluation of the Safety Climate at AkzoNobel Site Stenungsund. Department of Product and Production Development Chalmers University of Technology: Göteborg.

Brown, R.L. \& Holmes H., (1986). The Use of a FactorAnalytic Procedure for Assessing the Validity of an Employee Safety Climate Model. Accident Analysis \& Prevention, 18 (6), 455-470.

CBI. (1991). CBI Developing a Safety Culture Confederation of British Industry. London.

Cooper, D., \& Phillips, R.A., (2004). Exploratory Analysis of the Safety Climate and Safety Behavior Relationship. Journal of Safety Research, 35(5), 497-512.

Cooper, D., (2000). Towards A Model of Safety Culture. Safety Science, 36 (2), 111-136.

Cox, S., \& Flin, R., (1998). Safety Culture: Philosopher's Stone or Man of Straw? Work and Stress, 12(3), 189201.

Dedobbeleer, N., \& Béland, F. (1991). A Safety Climate Measure for Construction Sites. Journal of Safety Research. 22 (2), 97-103.

Dejoy, D.M. (1994). Managing Safety in the Workplace: An Attribution Theory Analysis and Model. Journal Of Safety Research, 25, 3-17.

Europeon Commission, (2014); Sağlık Sektöründe İş Sağlığı Ve Güvenliği Riskleri, (Çev: Prof.Dr. Mithat Kıyak), İstanbul: Okan Üniversitesi Yayınlar. 
Flin, R., Mearns, K., O’Connor, P., \& Bryden, R., (2000). Measuring Safety Climate: Identifying The Common Features. Safety Science, 34, 177-192.

Gershon, R. R. M., Karkashian, C.D., Grosch, J.W. v.d. (2000). Hospital Safety Climate and Its Relationship with Safe Work Practices and Workplace Exposure Incidents. (AJIC) Am J Infect Control, 28 ( 3), 211-221.

Glendon, A.I., \& Litherland, D.K. (2001). Safety Climate Factors, Group Differences And Safety Behaviour In Rood Construction. Safety Science 39, 157-188

Grıffin, M.A., \& Neal, A. (2000). Perceptions of Safety At Work: A Framework For Linking Safety Climate To Safety Performance. Knowledge and Motivation, Journal of Occupational Health Psychology, 5(3), 347-358.

Guldenmund, F.W. (2000). The Nature Of Safety Culture: A Review Of Theory and Research. Safety Science, 34, 215-257.

Hale, A. R., \& Hovden, J. (1998). Management and Culture: The Third Age Of Safety, A Review Of Approaches To Organizational Aspects Of Safety, Health And Environment In: Feyer, A.-M. \& Williamson, A. (Eds.). Occupational Injury Risk Prevention And Intervention, London: Taylor \& Francis.

Hofmann, D.A., \& Stetzer, A. (1996). A Cross-Level Investigation Of Factors Inuencing Unsafe Behaviors And Accidents Personnel, Psychology, 49, 307-339.

Hudson, P. (1999). Safety Culture: Theory and Practice. Leiden.

IAEA (1988). International Atomic Energy Agency Vienna.

IAEA (1991). Safety Culture, International Safety Advisory Group Safety Series 75 INSAG-4 (Vienna: IAEA).

International Nuclear Safety Advisory Group (INSAG). (1988). Basic Safety Principles for Nuclear Power Plants, Safety Series No. 75-INSAG-3, IAEA. Vienna.

Neal, A., Griffin, M.A. \& Hart P.M. (2000). The Impact of Organizational Climate on Safety Climate and Individual Behavior. Safety Science, 34(1), 99-109.

Niskanen, T. (1994). Assessing The Safety Environment In The Work Organization Of Road Maintenance Jobs. Accident Analysis and Prevention, 26, 27-39.

O. S. H. A. (Occupational Safety \& Health Administration). Healthcare. https:/www. osha.gov/SLTC/ healthcarefacilities/index.html (Erişim Tarihi: 19.06.2017)

Özkan, T. \& Lajunen T. (2003). Güvenlik Kültürü ve
İklimi. PiVOLKA, 2(10), 3-4.

Saygun, M., (2012) Sağlık Çalışanlarında İş Sağlığı ve Güvenliği Sorunları. TAV Preventive Medicine Bulletin, 11 (4), 373-382

Sekaran, U., (2003). Research Methods for Business: A Skill-building Approach. Fourth Ed. New York: John Wiley \& Sons, Inc., p. 288.

Törner, M. (2010). Systematic Review Good Interplay And Interaction Creates Security Climate And Culture In The Workplace. Work Environment Authority.

Turner, B. A., Pidgeon, N. F., Blockley D. I. \& Toft B. (1989). Safety Culture: Its Position In Future Risk Management, Paper Presented At The Second World Bank Workshop On Safety Control And Risk Management. Karlstad, Sweden.

Tüzüner, V.L., \& Özaslan, B. Ö. (2011). Hastanelerde İş Sağlığı ve Güvenliği Uygulamalarının Değerlendirilmesine Yönelik Bir Araştırma. İstanbul Üniversitesi İ̧letme Fakültesi Dergisi, 40 (2), 138-154.

Wiegmann, D.A., Zhang, H., Von Thaden, T., Sharma, G., \& Mitchell, A., (2002). A Synthesis of Safety Culture and Safety Climate Research, Technical Report ARL-02-3/FAA-02-2. Federal Aviation Administration Atlantic City International Airport, NJ., University of Illinois, 1-20.

Zohar, D., (1980). Safety Climate in Industrial Organizations: Theoretical and Applied Implications. Journal of Applied Psychology, 65, 96-102 


\section{EK: HASTANE GÜVENLİK TEDBİRLERİNE UYMA DAVRANIŞI ÖLÇEĞİ}

\section{1: Hiçbir Zaman, 2: Nadiren, 3: Bazen, 4: Sıklıkla, 5: Her Zaman}

\begin{tabular}{|c|c|c|c|c|c|}
\hline 1. Kullanılmış kesici ve delici nesneleri keskin kaplarına atarım. & 1 & 2 & 3 & 4 & 5 \\
\hline 2. Bistüri veya diğer keskin nesneleri kullanırken özel bir dikkat gösteririm. & 1 & 2 & 3 & 4 & 5 \\
\hline 3. Kontamine olma ihtimali olan tüm malzemeleri, trbbi attk kovasına atarım. & 1 & 2 & 3 & 4 & 5 \\
\hline 4. Hastadan kan alma işlemi yaparken eldiven kullanırım. & 1 & 2 & 3 & 4 & 5 \\
\hline 5. Kan veya diğer vücut sıvılarına maruz kalma olasılığı durumunda tek kullanımlık eldiven kullanırım. & 1 & 2 & 3 & 4 & 5 \\
\hline $\begin{array}{l}\text { 6. Kan veya vücut sıvıları ile kontamine olma ihtimalim bulunan yerlerde çalışırken, bir şeyler yiyip } \\
\text { içmemeye özen gösteririm }\end{array}$ & 1 & 2 & 3 & 4 & 5 \\
\hline 7. Kanla kontamine olmuş iğneleri, yaralanmalara sebep olabilecek biçimde el ile geri kapatmam. & 1 & 2 & 3 & 4 & 5 \\
\hline 8. Steril eldivenleri çıkardıktan sonra ellerimi yıkarım. & 1 & 2 & 3 & 4 & 5 \\
\hline $\begin{array}{l}\text { 9. Enfeksiyon taşıyan hastaların tükürükleri ile temas etmiş olan tüm malzemeleri dezenfekte ederim/ } \\
\text { ettiririm. }\end{array}$ & 1 & 2 & 3 & 4 & 5 \\
\hline $\begin{array}{l}\text { 10. Kontaminasyona sebep olabilecek tüm sızınt, sıçrama, dökülme ve benzeri şeyleri, derhal bir de- } \\
\text { zenfektan ile temizlerim/temizletirim. }\end{array}$ & 1 & 2 & 3 & 4 & 5 \\
\hline 11. Hastaya dikiş atmakta kullanılan iğneleri, el değmeden keskin kaplarına atarım. & 1 & 2 & 3 & 4 & 5 \\
\hline $\begin{array}{l}\text { 12. Kıyafetlerime kan ve vücut sıvısı bulaşma ihtimali olan durumlardan korunmak için, koruyucu kıya- } \\
\text { fet giyerim. (örneğin: ameliyat yeşili) }\end{array}$ & 1 & 2 & 3 & 4 & 5 \\
\hline $\begin{array}{l}\text { 13. Çalışırken gözlerime bir şeylerin sıçrama veya bulaşma intimali olan durumlarda, koruyucu gözlük/ } \\
\text { siperlik kullanırım. }\end{array}$ & 1 & 2 & 3 & 4 & 5 \\
\hline 14. Çalışırken ağzıma bir şeylerin sıçrama veya bulaşma intimali olan durumlarda, maske kullanırım & 1 & 2 & 3 & 4 & 5 \\
\hline
\end{tabular}

